\title{
The internist during the COVID-19 pandemic
}

\author{
Antonino Mazzone, Laura Castelnovo, Antonio Tamburello, Paola Faggioli, Nicola Mumoli \\ Department of Internal Medicine, Legnano Hospital, ASST Ovest Milanese, Legnano (MI), Italy
}

\section{Dear Editor,}

In the wake of the novel coronavirus infection disease 2019 (COVID-19) pandemic, it is abundantly clear to all the necessity of studying the pathology and widespread health consequences associated with the virus.

However, what is much less clear is the impact of COVID-19 on specialist medical skills.

COVID-19 disrupted routines in hospitals, healthcare institutions, and beyond. During the COVID-19 pandemic, Lombard Internal Medicine Departments, present in all the hospitals of the Lombardy Region were quickly and promptly reorganized, becoming primarily areas for the management of patients with severe acute respiratory syndrome coronavirus 2

Correspondence: Laura Castelnovo, Department of Internal Medicine, Legnano Hospital, ASST Ovest Milanese, Legnano Hospital, via Papa Giovanni Paolo II, 20025 Legnano (MI), Italy.

E-mail: laura.castelnovo@asst-ovestmi.it

Key words: COVID-19; internal medicine; multisystemic disease; holistic approach.

Acknowledgments: we thank all our staff and all our collaborators, who have actively and painstakingly engaged in this pandemic.

Conflict of interests: the authors declare no potential conflict of interests.

Ethical Statement: the authors are accountable for all aspects of the work in ensuring that questions related to the accuracy or integrity of any part of the work are appropriately investigated and resolved.

Received for publication: 10 September 2020.

Revision received: 15 September 2020.

Accepted for publication: 15 September 2020.

This work is licensed under a Creative Commons Attribution NonCommercial 4.0 License (CC BY-NC 4.0).

${ }^{\circ}$ Copyright: the Author(s), 2020

Licensee PAGEPress, Italy

Italian Journal of Medicine 2020; 14:251-252

doi:10.4081/itjm.2020.1368
(SARS-CoV-2) pneumonia. ${ }^{1}$ This because, as the numerous recent studies, also published by our group, have shown, SARS-CoV-2 disease showed a clinical and pathophysiological picture very similar to that of inflammatory diseases with multisystemic involvement and organ damage that went from vasculitic skin damage $^{2}$ to microangiopathic and thrombotic damage. ${ }^{3,4}$ This is due to the cytokine storm development inducing extensive lung damage in which cells of the inflammatory cascade play a fundamental role as known in viral and bacterial infections. ${ }^{5}$

A significant number of patients with pneumonia required oxygen therapy with non-invasive ventilation or high-flow nasal oxygen therapy, specific pharmacological treatment, and knowledge was required, too. This is the reason why a holistic approach to the patient remains fundamental and decisive.

A life spent as a midfielder, getting balls (C-PAP) back and making lungs work, is a paraphrase freely taken from Una vita da Mediano, a song by Luciano Ligabue (Italian singer) representing an excellent metaphor for what has happened in our working life, as most of the patients were hospitalized in the Internal Medicine wards. For this reason, Internal Medicine immediately had to make organizational changes. The levels of assistance have been differentiated, and areas of high intensity of care have been created; in them, those patients with respiratory failure needing continuous positive airway pressure (C-PAP) therapy were managed. Obviously, this new organization required a greater intensity of care and assistance, finding us to treat a higher number of patients admitted to Intensive Care Units than usual, as can be seen from the survey previously reported, carried out in several Internal Medicines throughout Lombardy. ${ }^{1}$

Internists, with their holistic vision of Medicine, have fought a great battle against COVID-19.

Modern medicine is slowly getting ready to fight this new pandemic. The only possible key is a holistic approach to the patient. If it were not for the presence of the Departments of Internal Medicine in Lombardy hospitals, the health system would not have resisted the emergency and collapsed. ${ }^{6}$ Internists were like the midfielder of a football team; they changed their institutional role, to recover the ball (C-PAP), and improve lung function, treating pneumonia that they have al- 
ways known how to cure. Moreover, internists are as midfielders in a football match, that are basic for achieving the final victory but never appear and always work behind the lines of the attackers. Hence, even more on other historical occasions, this emergency emphasized, even more, the strategic role of Internal Medicine in Italian Healthcare.

\section{References}

1. Mazzone A, Mumoli N. Reorganizing Italian Internal Medicine wards for COVID 19. Eur J Intern Med 2020 Apr 30. pii:S0953-6205(20)30180-1 [Epub ahead of print, doi: 10.1016/j.ejim.2020.04.059].

2. Castelnovo L, Capelli F, Tamburello A, et al. Symmetric cutaneous vasculitis in COVID-19 pneumonia. J Eur Acad Dermatol Venereol 2020;34:e362-3.

3. Mazzone A, Castelnovo L, Tamburello A, et al. Monocytes could be a bridge from inflammation to thrombosis on COVID-19 injury: A case report. Thrombosis Update 2020-12 [Epub ahead of print, doi: doi.org/10.1016/j.tru. 2020.100007].

4. Mumoli N, Vitale J, Mazzone A. Clinical immunity in discharged medical patients with COVID-19. Int J Infect Dis 2020;99:229-30.

5. Gatti A, Radrizzani D, Viganò P, et al. Decrease of nonclassical and intermediate monocyte subsets in severe acute SARS-CoV-2 Infection. Cytometry A 2020;97: 887-90.

6. Lenti MV, Corazza GR, Di Sabatino A. Carving out a place for internal medicine during COVID-19 epidemic in Italy. J Intern Med 2020 Apr 15 [Epub ahead of print, doi:10.1111/joim.13079]. 